\title{
Building System Design for Development of Automated Interior Finishing System - WASCOR IV Research Project Report (Part II) -
}

Naohisa Sunaga ${ }^{1}$, Yukio Hasegawa $^{2}$, Kinya Tamaki $^{3}$, Hiroshi Kasai ${ }^{4}$, Hiroshi Kurita ${ }^{1}$, Tatsuo Murayama ${ }^{5}$, Hitoshi Sugiura ${ }^{6}$, Teruo Yomo ${ }^{6}$, Masashi Matsudo ${ }^{7}$

${ }^{1}$ Shimizu Corporation,

${ }^{2}$ System Sience Institute, Waseda University,

${ }^{3}$ Aoyama Gakuin University,

${ }^{4}$ Kajima Corporation,

${ }^{5}$ Taisei Corporation,

${ }^{G}$ Hazama Corporation,

${ }^{7}$ Fujita Corporation, JAPAN

\begin{abstract}
For the development of automated building construction system with robots, the WASCOR (WASeda COnstruction Robot) research project has been organized since 1982 by the System Science Institute, Waseda University. The WASCOR IV project started in 1992. The research theme of the WASCOR IV project is to develop automated construction systems for interior finishing work. This research theme consists of the three sub-themes: 1) development of new building systems and construction methods which increase the consructability of construction robots, 2) design of the hardware of the system, and 3) design of the computer-assisted system for information management and machinery control. Concerning the first sub-theme, this paper discusses : methodology for the building system design of automated interior finishing work system. And a schematic plan for the model building is also described, which is presented in accordance with a building system and construction methods .
\end{abstract}

\section{INTRODUCTION}

The construction industry in Japan has to survive under the current severe business environment, and it is needed to change the building construction process in various aspects not only for labor saving and productivity improvement but also for safety, working environment, reducing industrial wastes and so on. On the other hand, for research or development of automated building construction system, it becomes clear that an approach from the level of the whole building construction is more efficient than approaches like developments of construction robots for single task.

From these viewpoints, one may say that now is the time to make the scenario of the future building construction system and to make clear the key-technology which will be 
With respect to steel work, some automated building construction systems have been developed and applied to real construction sites. These trials have made clear more and more the subjects which have to be overcome and the key technology. Interior finishing work treats various kinds of materials and parts, and has a great number of processes within the small work space. Therefore, there are few construction robots developed for interior finishing work and very few research concerning automated construction system from the level of whole interior finishing work.

For the reasons mentioned above, the WASCOR IV project has started in 1992 for development of automated construction systems for interior finishing work. As a subtheme of this research, an attempt was made to develop a new building system and construction methods of interior finishing work which increase the consructability of construction robots.

This paper describes a methodology of the building system design of automated interior finishing work system. And a schematic plan for the model building is also described, which is presented in accordance with a building system and construction methods .

\section{DESIGN POLICY FOR AUTOMATED INTERIOR FINISHING WORK SYSTEMS}

As mentioned above, it is needed to change the building construction process in various aspects. In designing the automated building construction system, therefore, the design policy must be settled clearly, and the design work must be proceeded based on it.

The design policy for the automated building construction system consists of the following items:

1. Increase the efficiency of the whole production process, instead of minor optimization.

2. Simplification of the complicated works.

3. Reduction of work trades and man hour at both prefabricating factories and a site.

4. Reduction of hazardous and hard works for workers

5. Utilization of the design data and the planning data to achieve more effective automated systems for operational instructions and measurements.

6. Reduction of industrial wastes from the construction sites.

7. Adequate cooperation between workers and robots.

8. Use of new technologies which could be available within ten years.

\section{BUILDING SYSTEM DESIGN OF AUTOMATED INTERIOR FINISHING WORK SYSTEMS}

\section{1. Basic concept}

On the basis of the design policy, over 50 types of ideas of new building systems and construction methods were listed, and 10 ideas were expanded into the schematic plans of automated interior finishing work system. The examples of the schematic plans are presented in Figure 1. Further details of the research procedurewas reported in the 
WASCOR IV report Part I at the 11th ISARC. The basic concept for the building system design of automated interior finishing work systems was decided from common concept of ten schematic plans as follows:

Assembly of the prefabricated interior units which include interior finishing materials, facilities and structural menbers.

In the following subsections, the viewpoints for designing the prefabricated interior units and the strategy of the building system design are described.

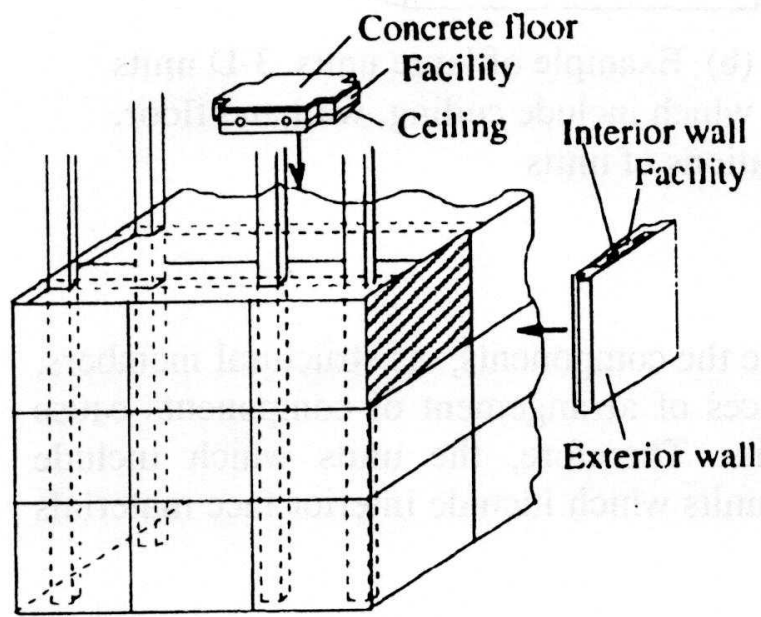

(a) Assembly of units which include structural members, interior materials and fasilities.

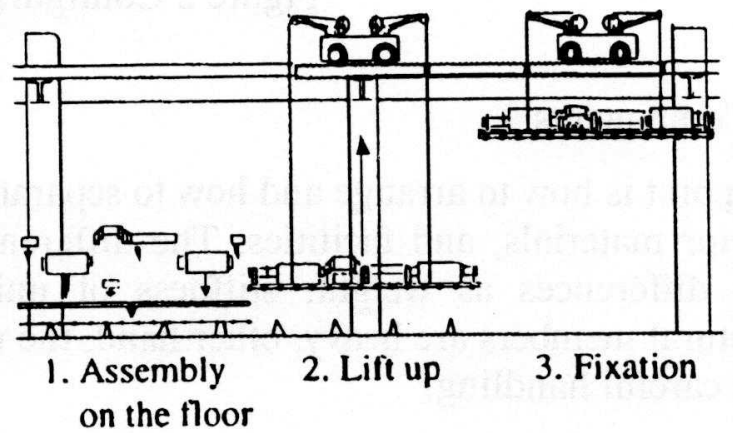

(b) Lifting up the units assembled on the floor.

Figure 1 Examples of schematic plans of automated interior finishing system

\section{2 Viewpoints for design of the interior units}

Assembly of the prefabricated units is one of the most common ways for rationalization of production process, in fact, it is easy to find examples of it in the present construction methods. But the different unit designs and assembly processes cause a great difference. Therefore, it is very important to find the most suitable design and assembly of the units for the building.

There are many factors in design of the interior units, it is very difficult to find the optimum result. For this reason, these factors were divided into three large groups. Three viewpoints for design of the interior units are 1) configuration of units, 2) components of units, and 3) assembly methods of units.

\section{(1) Dimensions}

Two types of configuration of units can be considered in the trend of the units for building construction. Figure 2 shows the trend of configuration of units. With regard to interior finishing units, one is the small plate units for each part of interior spaces, another is the large 3-D units which consist of the three types of face: ceiling, wall, and floor. These two types of units are quite different each other in its figure, size and weight, therefore, the construction methods for these units would completely different. 


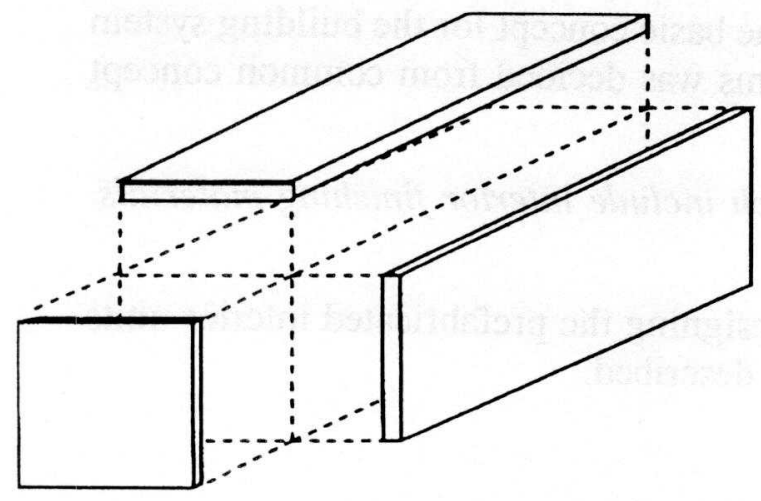

(a) Example of small units. Plate units for each part of interior spaces.

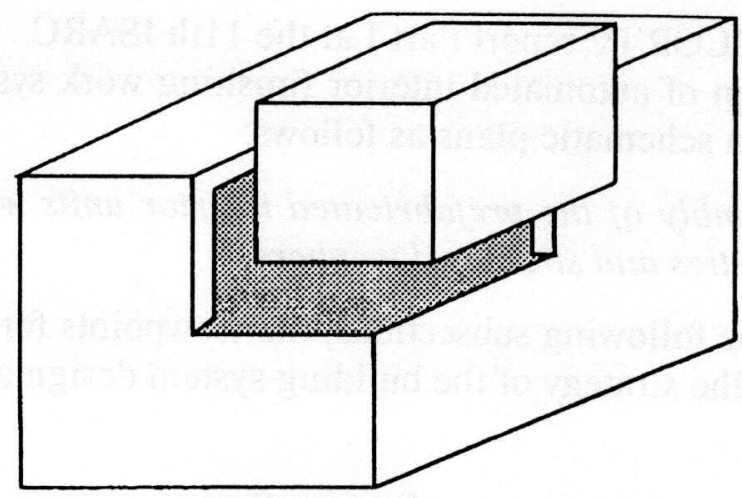

(b) Example of large units. 3-D units which include ceiling, wall, and floor.

Figure 2 Configurations of units

\section{(2) Components}

The point is how to arrange and how to separate the components, as structural members, Interior materials, and facilities. The differences of arrangement of components cause such differences as weight, stiffness of units. Therefore, the units which include structural members are heavy, other hand, the units which include interior face materials need careful handling.

(3) Assembly method

Concerning the assembly, there are several points of view, as sequence, access directions of assembly, and design of joints. In this stage, the most important factor is the access directions in assembling units. (Figure 3)

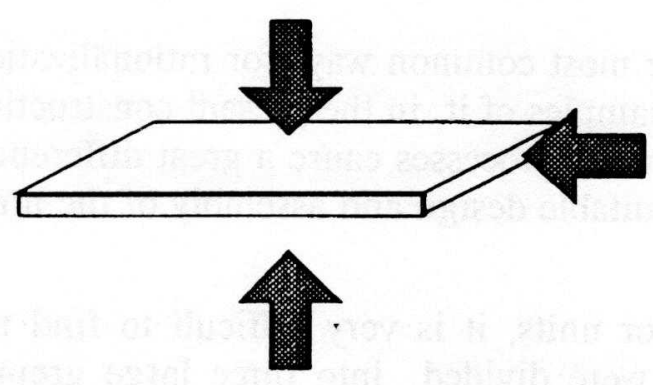

(a) In case of horizontal units

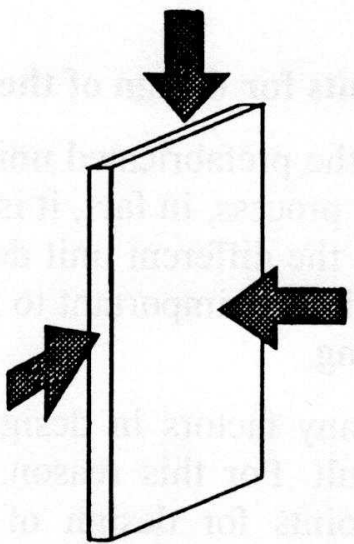

(b) In case of vertical units.

Figure 3 Directions for instalation of the interior units

\subsection{Strategy for building system design of automated interior finishing systems}

Figure 4 shows a flow chart of the strategy for building system design of automated interior finishing systems in this research project. The strategy consists of three large steps. 
1) The schematic plans ( building system and construction methods ) of automated interior finishing work systems are categorized systematically from the three viewpoints above mentioned. Figure 5 shows the simple schema of classification of the schematic plans. Each small cube means a schematic plan.

2) Since schematic plans are logical combinations of three factors, a great number of schematic plans exist, and some of them are unrealizable. However, once such condition as concrete design of the building is settled, it is easy to select the categories and to reduce the number of schematic plans. Therefore, next step is selection of the categories with a standard of judgment, the design policy above mentioned.

3) Finally, the schematic plans are evaluated, then, the optimum schematic plan for the building is selected. For the evaluation, the design policy is broken down into more concrete evaluation items.

1. Classifying the unit designs systematically.

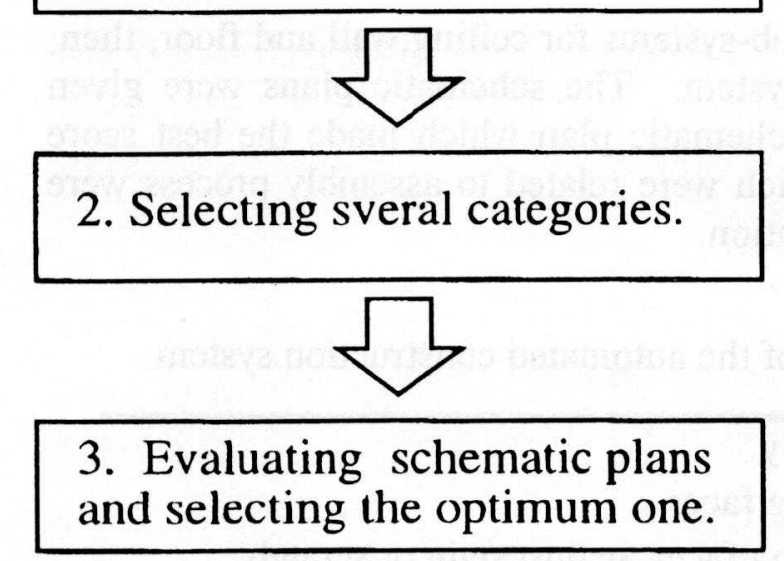

Figure 4 Strategy of building system design of automated interior finishing systems.

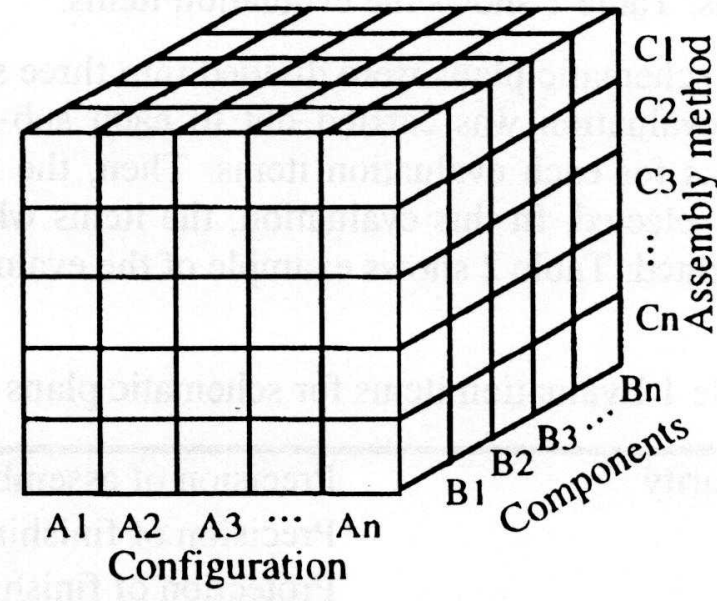

Figure 5 Simple schema of classification of schematic plans

\section{AUTOMATED INTERIOR FINISHING SYSTEM FOR A MODEL BUILDING}

\subsection{Model building}

Based on a static survey, a model building is set up in order to prescribe concrete design conditions. This type of the medium-rise office building is one of the most common in Japan which has the following specifications: steel structure, 10 stories, $1200 \mathrm{~m}^{2}$ typical floor area and so on.

\subsection{Selection of categories}

On the conditions of the model building, several categories are selected.

(1) Configuration

For the following reasons, the plate type unit for each part of interior is chosen. 
Firstly, this type of units could flexibly correspond with the existing automated building construction systems for structural work. Secondly, there are big differences of weight, stiffness of the three parts, as ceiling, wall, and floor. Separation of the parts of interior space leads to easier design of units and more loose handling conditions. Thirdly, the 3$\mathrm{D}$ type unit is not suited for the long-span beam structure of the office building.

(2) Components

In order to reduce the lifting works or the works at high place, almost all of the facilities are concentrated in the units on the floor.

(3) Assembly method

For reasons of assembly sequences or unit weights, some categories were excluded.

\subsection{Evaluation}

For the evaluation, the design policy was broken down into more concrete evaluation items. Table 1 shows the evaluation items.

The schematic plans were divided into three sub-systems for ceiling,wall,and floor, then, the evaluation was carried out to each sub-system. The schematic plans were given marks for each evaluation items. Then, the schematic plan which made the best score was selected. In this evaluation, the items which were related to assembly process were weighted. Table 2 shows example of the evaluation.

Table 1 Evaluation items for schematic plans of the automated construction system

\begin{tabular}{ll}
\hline Quarity & Precision of assembly \\
& $\begin{array}{l}\text { Precision of finishing faces } \\
\text { Protection of finishing faces against stain or scratch }\end{array}$ \\
\hline Man hour & $\begin{array}{l}\text { Man hour in factories } \\
\text { Man hour for preparation at sites } \\
\\
\text { Man hour at sites }\end{array}$ \\
\hline Safety & Safety for workers \\
\hline Working environment & Working environment ( dirt, vibration, noise, weather) \\
& Required surrounding spaces \\
\hline Workability & Assembly ease (positionning, assembly ) \\
& Handling ease of members and units \\
& Rework \\
\hline Material handring & Transportations from factories to sitcs \\
& Conveyances in a sitc \\
\hline Environment & Industrial wastes \\
\hline Others & Flexibility of system ( range of application, re-usc) \\
& Ease of installation of robots or machineries \\
\hline
\end{tabular}


Table 2 An evaluation example of schematic plans

\begin{tabular}{|c|c|c|c|c|c|c|c|c|c|c|c|c|c|c|}
\hline \multicolumn{2}{|r|}{ Evaluation items } & \multirow{2}{*}{$\frac{\text { Wcisht }}{2}$} & \multicolumn{2}{|c|}{ Sysicm I } & \multicolumn{2}{|c|}{ Systcm II } & \multicolumn{2}{|c|}{ Sysicm III } & \multicolumn{2}{|c|}{ System IV } & \multicolumn{2}{|c|}{ Sysietn V } & \multicolumn{2}{|c|}{ Sysicin VI } \\
\hline \multirow[t]{3}{*}{ Quarity } & Precision of asscmbly & & 6 & 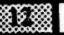 & 10 & 梦 & 10 & 18. & 10 & 300 & IX & 3. & 15 & s. \\
\hline & Prccision of tinishing taccs & 3 & & 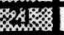 & 15 & 6 & 12 & ros & 13 & 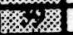 & 18 & s & $T 4$ & 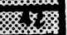 \\
\hline & Protcction of finishing faces & 3 & 6 & 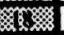 & 18 & x桨 & 14 & 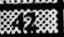 & II & 管筑 & 18 & $x^{2}$ & 15 & 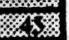 \\
\hline \multirow[t]{3}{*}{ Man hour } & Man hour in factorics & 2 & 8 & 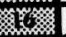 & II & 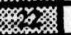 & 12 & 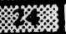 & 12 & 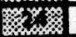 & 18 & 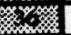 & 18 & 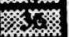 \\
\hline & Man hour for preparation & 3 & $\overline{8}$ & 桨婉 & I0 & 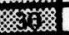 & 10 & 筮新 & 9 & 曼 & 14 & 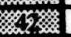 & 15 & 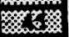 \\
\hline & Man hour at sites & 3 & 17 & 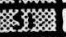 & 14 & 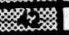 & 13 & Fry & 14 & 2x & 7 & 然妙 & $\bar{B}$ & 櫈 \\
\hline Saficly & Safcty for workers & 1 & 12 & 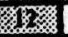 & 13 & 梦 & 13 & 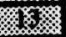 & 1.3 & Kros & 16 & 桨6 & 16 & s. \\
\hline \multirow{2}{*}{$\begin{array}{l}\text { Workinh } \\
\text { environment }\end{array}$} & Working environment & 1 & 7 & 桨 & $x$ & 登掼 & 9 & 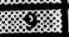 & 14 & 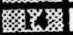 & Ix & 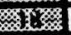 & 18 & 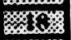 \\
\hline & Required surrounding spaces & 2 & 6 & 桑多紧 & $\bar{x}$ & 86 & $\bar{x}$ & rom & 10 & 2003 & 15 & 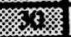 & 15 & 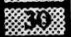 \\
\hline \multirow[t]{3}{*}{ Workability } & Asscmbly casc & 3 & 6 & 叕 & $\pi$ & s; & 10 & 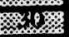 & TO & 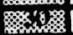 & 16 & 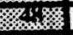 & 15 & 8 \\
\hline & Handling case & 3 & 6 & 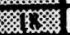 & 9 & 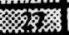 & $\overline{8}$ & 祭积器 & $\pi$ & 策薙 & 16 & 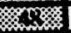 & 17 & 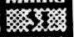 \\
\hline & Rework & 2 & 6 & 好 & Ti) & 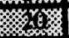 & $\bar{y}$ & 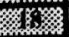 & 13 & 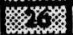 & 15 & 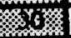 & 14 & 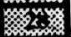 \\
\hline \multirow{2}{*}{$\begin{array}{l}\text { Matcrial } \\
\text { handring }\end{array}$} & Transportations to sices & 2 & 6 & 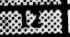 & $\pi$ & 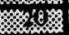 & $\pi$ & 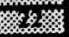 & T4 & sis & $T T$ & 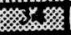 & TR & 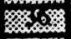 \\
\hline & Conveyances in a sitc & 2 & 6 & 格经 & 10 & 280 & 10 & 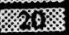 & 12 & $2 \%$ & 18 & 器证 & 18 & 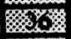 \\
\hline Environment & Industrial wastes & 1 & 12 & 要骨 & 13 & 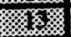 & 14 & Yrox & 13 & 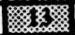 & 13 & 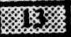 & 13 & 怒怒 \\
\hline \multirow[t]{2}{*}{ Others } & Flexibility of svstem & 1 & $\bar{x}$ & 桨要 & 11 & 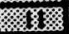 & 9 & $8 \%$ & III & 3 & 15 & K & $y$ & 叕 \\
\hline & Easc of installation of robots & 3 & 8 & 覴純 & 13 & 好3. & 14 & $3 \%$ & 13 & S6\% & 13 & 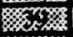 & 14 & mis \\
\hline & Total & & 123 & 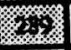 & 174 & 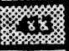 & 165 & 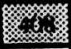 & 174 & 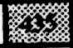 & 2.30 & 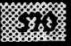 & 216 & 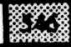 \\
\hline & Ranking & & & 6 & & 4 & & 5 & & 3 & & 1 & & 2 \\
\hline
\end{tabular}

\subsection{Schematic plan of a automated interior finishing work system}

The schematic plan of a automated interior finishing work system in the WASCOR research project is described form the following two points: 1) interior units, 2) layout of facilities.

(1) Interior units

The image of the automated interior finishing work system is shown in figure 6.

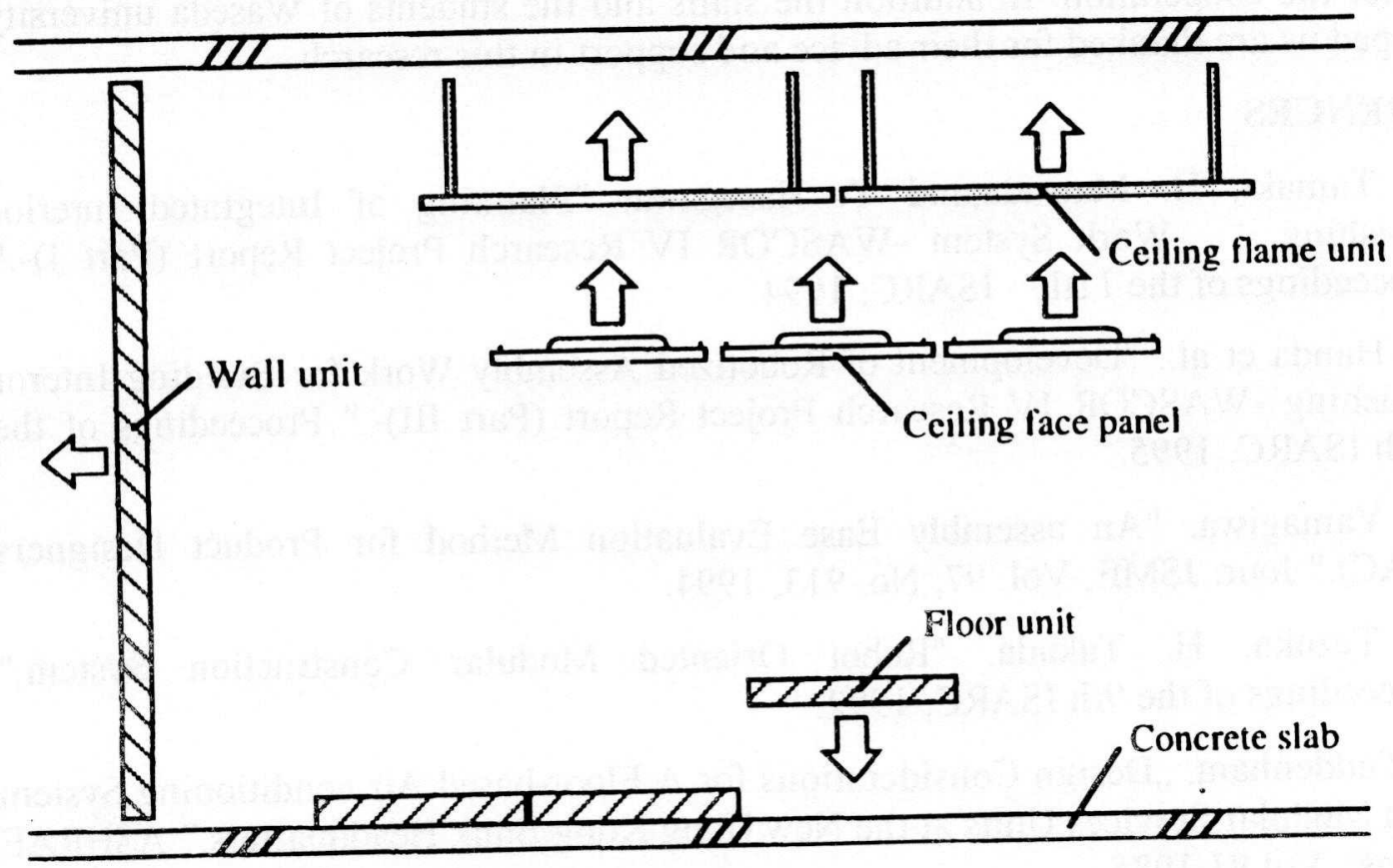

Figure 6 Schematic plan of the automated interior finishing system 
The system consists of three large sub-systems: the ceiling system, wall system, and floor system. The interior units includes both interior materials and facilities. Each unit is installed to the fixed position in the access direction shown in the figure.

(2) Layout of facilities

The point is that almost all of the facilities are basically concentrated in the floor box units on concrete slab. The floor based air conditioning system is introduced, which is now under development and expected as an air conditioning system in the near future.

\section{SUMMARY}

An attempt was made in the WASCOR IV research project to develop the automated interior finishing work system which increases the consructability of construction robots and other machineries.

A methodology for the building system design of automated interior finishing work system has been discussed. And a schematic plan of building system and construction methods for the model building has been also described. The further details of the system is described in the WASCOR IV report part III at the 12th ISARC.

\section{ACKNOWLEDGEMENT}

This research is a part of the WASCOR research project, a multi-client research project organized by the System Sience Institute of Waseda University and the following 11 companies: Fujita Corporation, Hazama Corporation, Hitachi Zosen Corporation, Kajima Corporation, Kumagai Gumi Corporation, Sato Kogyo Corporation, Taisei Corporation, Toda Corporation, Tokyu Corporation, Komatsu Corporation, Shimizu Corporation. The authors would like to express their thanks to the members of the project for the cooperation. In addition the staffs and the students of Waseda university who helped us are thanked for their advice and support in this research.

\section{REFERENCES}

[1] K. Tamaki, H. Matsuda,and Y. Hasegawa. "Planning of Integrated Interior Finishing Work System -WASCOR IV Research Project Report (Part I)-." Proceedings of the 11th ISARC, 1994.

[2] M. Handa et al.. "Development of Robotized Assembly Work for Building Interor Finishing -WASCOR IV Research Project Report (Part III)-." Proceedings of the 12th ISARC, 1995.

[3] Y. Yamagiwa. "An assembly Ease Evaluation Method for Product Designers (DAC)." Jour. JSME, Vol. 97, No. 913, 1994.

[4] T. Tezuka, H. Takada. "Robot Oriented Modular Construction System." Proceedings of the 9th ISARC, 1992.

[5] D. Tuddenham. „Design Considerations for A Floor-based Air conditioning System with Modular Services Units at the New Hong Kong Bank Headquarters." ASHRAE Trans., Vol.91,1985. 